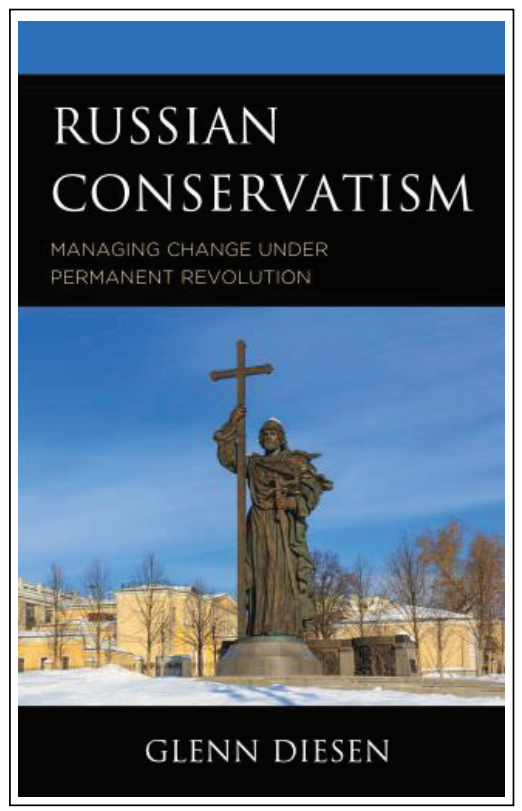

\title{
Russian Conservatism: Managing Change under Permanent Revolution
}

\author{
Glenn Diesen \\ Lanham, MD: Rowman \& Littlefield 2021 \\ 256 sidor. ISBN 9781538149980
}

Recenserad av Susanna Rabow-Edling [docent i statsvetenskap, Institutet för Rysslands- och Eurasienstudier, Uppsala universitet, susanna. rabow-edling@ires.uu.se]

Under de senaste 20 åren har konservatismen blivit en allt starkare kraft i Ryssland. Från början växte den fram som en ideologisk rörelse bland intellektuella som reagerade på 1990-talets liberala chockterapi, men på senare tid har konservativa idéer kommit att inkorporeras i den statliga ideologin. Rysk konservatism har dessutom blivit del av en transnationell rörelse mot den liberala internationella ordningen. Denna utveckling har återspeglats i utgivandet av en mängd böcker och artiklar om rysk konservatism både i Ryssland och i väst. Glenn Diesens bok är ett inlägg i denna diskussion och behandlar utvecklingen av rysk konservatism och dess förutsättningar från Kievriket till idag.

Diesen utgår ifrån en vedertagen syn på konservatism som en ideologi syftande till att hantera förändring, snarare än att bevara status quo. Enligt denna syn går det inte att motverka förändring då detta leder till stagnation. Men modernisering och samhällsförändring bör enligt konservativa begränsas och ske gradvis.

Syftet med Diesens bok är att visa hur konservatismen har utvecklats historiskt i Ryssland. Han använder två klassiska konservativa idéer som utgångspunkt. Den ena föreställningen går ut på att samhällsförändringar måste ske organiskt för att fungera, vilket innebär att alla reformer måste baseras på det som redan existerar: Det måste finnas en kontinuitet mellan modernisering och den ryska historien. Den andra idén som ingår i både konservativ och socialistisk kritik av liberalismen är att människan är en social varelse som har behov av att tillhöra en social grupp. Därför strävar hen 
efter att bevara kollektivet och reproducera socialt medlemskap i en grupp. Diesen menar att all förändring måste ta hänsyn till dessa "ursprungliga instinkter». Men även om all konservatism vilar på dessa antaganden utvecklar den sig på olika sätt i olika länder beroende på unika geografiska, kulturella och historiska förutsättningar. I det ryska fallet har konservatismen blivit influerad av autokrati, imperium och strävan att skilja sig från väst.

Diesens bok blir svårläst eftersom det är oklart om den utgör en samhällsanalys eller en partsinlaga i debatten om Rysslands framtid. Är syftet verkligen det författaren anger: att förklara utvecklingen av rysk konservatism, eller är det snarare att argumentera för den konservativa tesen att modernisering måste ske gradvis och växa organiskt ur rysk kultur och historia? Om man läser boken som en samhällsvetenskaplig analys föreligger några allvarliga brister. Till att börja med använder Diesen genomgående ideologiskt laddade idéer som analytiska begrepp. Hans ambition tycks inte vara att visa att rysk konservatism vilar på konservatismens "fundamentala och universella antaganden» utan att presentera dessa konservativa antaganden som objektivt sanna. Konsekvensen av detta blir att Diesen beskriver rysk historia genom en konservativ lins. Utmaningen för Ryssland uppges vara att de styrande inte har baserat samhällsförändringar på konservativa idéer om gradvis förändring. Det är i detta ljus som uttalanden som att Alexander II:s reformer »eventually brought down the Russian state in the Bolshevik Revolution» (s. 77-78) kan förstås.

Vidare är referensapparaten i boken bristfällig, vilket ofta gör det svårt att avgöra vems idéer som uttrycks. Är det konservativa tänkares idéer, Diesens personliga åsikter eller hans analys av konservatismen som presenteras (se till exempel s. 21, $25,48-49,57)$ ? Subjektiva värderingar och objektiv analys blandas (s. 37, 44, 78). En stor del av analysen vilar på konservativ sekundärlitteratur (främst västerländsk) samt på konservativa ryska tänkares egna analyser, vilket gör att utvecklingen av rysk konservatism presenteras med hjälp av ett konservativt narrativ. Ett exempel på detta är beskrivningen av Peter den stores reformer som tar formen av en konservativ kritik. Konsekvenserna av Peters reformer analyseras i huvudsak med hjälp av den konservative historikern Nikolaj Karamzin. På ett ställe skriver Diesen att "Karamzin recognised that modernisation and greatness must be built on a conservative foundation» (s. 51). Här tycks Diesen själv förfäkta konservativa idéer. Det finns även andra exempel på att Diesen anser att reformer bör vara organiska (s. 78, 95). Stundtals förvandlas boken till ett försvarstal för konservatism, som i inledningen där Diesen skriver: "Conservatism is imperative to ensure that a state does not degrade to a mere geographical description of a patch of land inhabited by people with no special connection. Change and modernisation must build on the culture and traditions that evolved over the centuries to preserve the nation and the civilizational distinctiveness» (s. 1), eller i kapitel 1 där han skriver "[t]he contemporary decoupling of liberalism from the nation-state in the West is deeply problematic» (s. 25). 
Boken saknar också en tydlig begreppsapparat, framför allt när det gäller det centrala begreppet konservatism. Detta begrepp används ibland för att beskriva idéer eller rörelser, ibland för att beskriva traditionalistisk politik, och ibland verkar det synonymt med autokratin. Här behövs bättre tydlighet vad begreppet betyder och hur det används i olika sammanhang samt hur det förändras över tid.

Slutligen har förlaget slarvat med sin textgranskning och redigering. För detta ska kanske författaren inte lastas. Snarare är det en följd av att många engelskspråkiga fackboksförlag på senare tid förvandlats till en industri som syftar till att producera så mycket som möjligt på kortast möjliga tid utan hänsyn till kvalitet. Men det innebär att boken är full av språkliga fel. Två exempel av många: "conservatives are more drawn to the identity of a civilisation state as it seized being an ethnic nationstate» (s. 8) och "others drew inspiration for Medival Muscovy» (s. 6).

Diesen har rätt i att det finns en tendens hos västerländska forskare att betrakta Ryssland som "den andre» (s. 8); att överdriva skillnader och tona ned likheter mellan väst och Ryssland. Det är därför en god ambition att försöka skildra ryska tänkares idéer inifrån utan att anlägga ett västerländskt fördömande perspektiv och Diesen gör det på ett inkännande sätt. Men för att detta ska lyckas kan inte tänkare plockas osystematiskt från olika tidsperioder utan att ta hänsyn till deras olika ståndpunkter eller den specifika historiska kontext de verkade i. Det går inte heller att helt undvika att förhålla sig till forskningsläget. Men framför allt kan man inte som forskare själv propagera för de idéer man samtidigt analyserar utan att tala om att detta är syftet. Denna kritik är förstås mindre relevant för den som väljer att läsa boken som ett argument för behovet av organisk förändring i Ryssland. 